\title{
RESPONSE TO RICHARD STEWART, “REMEDYING DISREGARD IN GLOBAL REGULATORY GOVERNANCE”
}

\author{
David Zaring*
}

The globalization of administration is the most interesting thing happening in both administrative and international law. Richard Stewart's article ${ }^{1}$ in the April 2014 issue of the American Journal of International Law is a brilliant tour of the horizon of the problems and prospects of this sort of lawmaking. It reflects the work he has done, along with Benedict Kingsbury, as a member of the Global Administrative Law (GAL) Project, ${ }^{2}$ housed at New York University Law School and joined by academics all over the world. I am a GAL fellow traveler, if not a paid member, and so I found the paper necessary. Global coordination is setting the standards for national administration in a vast array of issue areas, and surely is the most vibrant and rapidly developing form of international governance. It needs both organization and problematizing, and in this article, Stewart offers both.

Stewart has thought carefully about the ways to either encapsulate or solve the problems of the phenomenon, and by exploring both he has created a reference to which future work will turn when the parameters of global regulation are the subject. In what follows, I will review the claims made by the article and raise some questions about the problem of disregard that animates it.

As a descriptive matter, it:

- reviews the extent of global administrative law. As Stewart says, "[h]undreds or thousands of the special purpose global bodies exercise regulatory authority in different fields."

- claims that despite the diverse sorts of authorizations of the bodies-which come from treaties, from the domestic procedures undertaken by members of global regulatory networks, or from the quality of regulations issued by private standard setters - they can nonetheless usefully be understood as a common phenomenon of cross-border lawmaking.

- posits that the narrow focus of these various bodies makes them generally susceptible to the problem of disregard that is, disregard for the interests of those often affected by global regulation. Because many of those affected find it difficult to follow the process or because they come from the developing world, they do not participate in it.

- argues that the problem of disregard could be remedied by a strengthening of domestic oversight over international processes, or by creating an overarching global responsiveness regime. It could also be done by strengthening the good governance characteristics of global regulators themselves.

\footnotetext{
* Associate Professor of Legal Studies and Business Ethics at The Wharton School, University of Pennsylvania. Originally published online 5 Aug. 2014.

1 Richard B. Stewart, Remedying Disregard in Global Regulatory Governance: Accountability, Participation, and Responsiveness, 108 AJIL 211 (2014).

${ }^{2}$ Global Administrative Law Project, INST. FOR InT'L LAW AND JusticE: N.Y.U. SCHOOL OF LAW.
}

ASIL and David Zaring (C) 2014 
It is the last of these possible solutions that appeals most to Stewart. The solutions he offers are focused on the idea that global regulation can-although not without some discomfort-heal itself through better process.

- One such solution would be to use decisional rules to account for the disregarded, either by letting them participate in the decision or by forcing decision makers to consider their interests. Although there are problems with decisional approaches, Stewart appears to regard negotiated rulemaking, where all stakeholders deliberate over the appropriate global rule, to be a promising, if imperfect, way of avoiding disregard.

- Another solution would be to require global administrative decision makers to be held accountable, which can be done in a variety of ways. Most promisingly, legal accountability forces these decision makers to compare their regulatory products to the remit covered by their charter, treaty, or authorization.

- A third would be to use scrutiny to do the job, either by the market, by peers, or by anyone given sufficiently transparent procedures and reason-giving. This sort of scrutiny-based solution seems to be the one that Stewart finds the most promising.

Stewart is, I think, correct to observe that global regulation is increasingly comparable to straightforwardly law-governed international organizations, which, in turn, makes it increasingly susceptible to legal review. It is also probably the case that the best kind of good-governance help for these organizations would be scrutinyoriented help, which would depend on embracing a degree of transparency that might make global regulatory efforts vulnerable to scrutiny in a variety of unpredictable ways. That, however, is a feature, not a bug; if global regulatory efforts permit real scrutiny, possibly by unexpected but authoritative or persuasive actors in the international context, we can hope for creative forms of review, rather than simply relying on familiar stand-bys that even at their best fit uncomfortably with the nature of international governance.

However, when international governance problems are identified, one does not want to give up on the prospect of international governance solely because one can imagine more or better attention being paid to the disregarded. As always, the questions are: how serious is the problem? Compared to what?

For, increasingly, the standard tropes of administrative law are being observed by these global regulatory bodies. This does not make them legitimate in the way a free election in a democratic polity is, or even legitimate through presidential adoption or congressional imprimatur. But it does show that the new powers in global lawmaking are aware of the problems posed by their purely technocratic approach.

It may also be the case that as these bodies weave increasingly elaborate cross-border regulatory webs, they have no choice but to resort to something that looks quite law-like. In financial regulation, I view global administration as a sort of administration that has increasingly adopted stable bedrock principles that would be familiar to any international economic lawyer; indeed, given the importance of the cross-border work done to oversee financial institutions, it would be surprising if a measure of consistently applied rules, reasongiving, and transparency were not adopted. The banks being supervised would certainly find it arbitrary if done differently.

Moreover, the seriousness of the problem is a case that has to be made carefully. There are simple positive law reasons to worry about the problem of disregard in the American context. In American administrative law, a role for public participation is guaranteed by statute but is threatened when regulatory policy is made by cross-border deal.

Internationally, the question is a bit more complex. It is easy to talk about the regretability of a governance process that, say, for airplane safety, only really involves aeronautics companies, aeronautics engineers, and 
aeronautics regulators, almost all of whom live in twelve countries. But why is that not enough? In any domestic regulatory system, accountability and transparency are often nothing more than opportunities for the regulated industry to weigh in on the programs of their regulators. Plane passengers, Amnesty International, and the serried ranks of the chambers of commerce in the developing world have very little interest in participating in a regulatory process that covers airplane construction, provided that the process creates good outcomes. The participation rates of the cognate institutions in the United States when the Federal Aviation Administration opens a rulemaking to comment suggest that they feel the same way.

Global regulatory cooperation exacerbates the distance between the regulatory process and the public, to be sure. But when it involves technocratic questions, one wonders whether the disregard problem is always something worth solving, even though it can be identified. And as for the dispossessed-either the citizens of developing economies or the citizens of developing economies unable to keep track of the regulatory deals that may have been cut by the technical agencies responding to globalization-one wonders whether the (quite strong) case must be made that their needs should be taken into account before global progress is made. After all, the alternative is that a form of global governance that is currently prospering and real could be ossified by procedural requirements affording regard to those uninterested in it. 